\title{
Avaliação do ciclo de vida da cadeia no coprocessamento de resíduos industriais
}

O coprocessamento tem sido considerado um duplo ganho, convergindo os interesses dos geradores de resíduos que necessitam tratar e dispor os seus resíduos com a demanda energética das indústrias de cimento. O objetivo geral do estudo é identificar os principais impactos ambientais da cadeia do processamento de resíduos industriais na produção de clínquer. A metodologia consistiu no emprego da Avaliação do Ciclo de Vida (ACV). A abordagem foi a do berço ao portão e a unidade funcional foi a produção de uma tonelada de Clínquer. O método de Avaliação do Impacto a escolhido foi o ReCiPe e os dados submetidos à caracterização, normalização e ponderação utilizando três grupos diferentes e por fim submetido ao mixing triangle. Os resultados do inventário demonstraram que: (1) o coque de petróleo, o metal ferro e o recurso natural água foram as principais entradas; e (2) as emissões de dióxido de carbono, nitrato e cipermetrina foram as principais emissões para o ar, o solo e a água, respectivamente. A caracterização apontou que a blendeira foi responsável pela maioria dos impactos de ponto médio, com exceção da Toxicidade Humana, Ecotoxicidade Marinha, Depleção Fóssil e Mudanças Climáticas. A normalização apontou a Toxicidade Humana como o principal impacto na etapa da clinquerização. Conclui-se que o impacto à saúde humana em ponto final é o principal em toda a cadeia estudada. Tal constatação permite observar primeiramente que a causa principal está nas substâncias tóxicas existentes nos resíduos industriais, culminando em riscos ocupacionais na blendagem e potencializando-se na queima do resíduo no forno de clínquer.

Palavras-chave: Avaliação do Ciclo de Vida; Coprocessamento; Clínquer; Impactos Ambientais; Saúde Humana.

\section{Life cycle assessment of the co-processing chain of industrial waste}

Co-processing has been considered a double gain, converging the interests of waste generators who need to treat and dispose of their waste with the energy demand of the cement industries. The general objective of the study is to identify the main environmental impacts of the industrial waste processing chain in the production of clinker. The methodology consisted of using Life Cycle Assessment (LCA). The approach was from the cradle to the gate and the functional unit was the production of one ton of clinker. The chosen Impact Assessment method was ReCiPe and the data submitted to characterization, normalization and weightin using three different groups and finally submitted to the mixing triangle. The results of the inventory showed that: (1) petroleum coke, metal iron and the natural resource water were the main inputs; and (2) emissions of carbon dioxide, nitrate and cypermethrin were the main emissions to air, soil and water, respectively. The characterization pointed out that the blendeira was responsible for most of the midpoint impacts, with the exception of Human Toxicity, Marine Ecotoxicity, Fossil Depletion and Climate Change. Normalization pointed to Human Toxicity as the main impact in the clinker kiln stage. It is concluded that the impact on human health at the end point is the main one in the entire studied chain. This observation allows us to first observe that the main cause is the toxic substances found in industrial residues, culminating in occupational risks in the blending and increasing the burning of the waste in the clinker oven.

Keywords: Life Cycle Assessment; Co-processing; Clinker; Environmental impacts; Human Health.

\section{Topic: Engenharia Ambiental}

Reviewed anonymously in the process of blind peer.
Received: 03/06/2021

Approved: 27/06/2021
David Barreto de Aguiar (iD)

Universidade do Estado do Rio de Janeiro, Brasil

http://lattes.cnpq.br/7229051875249959

http://orcid.org/0000-0003-1233-0253

david.aguiar@ifri.edu.br

Ubirajara Aluizio de Oliveira Mattos

Universidade do Estado do Rio de Janeiro, Brasil

http://lattes.cnpq.br/4965089463046103

http://orcid.org/0000-0002-2689-2110

ubirajaraaluizio@yahoo.com.br

Victor Paulo Peçanha Esteves (iD)

Universidade Federal do Rio de Janeiro, Brasil

http://lattes.cnpq.br/7858887034547590

http://orcid.org/0000-0002-6812-4558

victoresteves@poli.ufri.br
Referencing this:

AGUIAR, D. B.; MATTOS, U. A. O.; ESTEVES, V. P. P.. Avaliação do ciclo de vida da cadeia no coprocessamento de resíduos industriais. Revista Ibero Americana de Ciências Ambientais, v.12, n.6, p.377-386, 2021. DOI: http://doi.org/10.6008/CBPC2179-6858.2021.006.0031 


\section{INTRODUÇÃO}

O coprocessamento tem sido considerado um duplo ganho, convergindo os interesses dos geradores de resíduos que necessitam tratar e dispor os seus resíduos com a demanda das indústrias de cimento pelo seu alto consumo de materiais e combustíveis para a fabricação do produto, apresentando grande potencial para economizar o uso de recursos naturais não renováveis, acarretando na redução da emissão de gases do efeito estufa (BOESCH et al., 2010; LAMAS et al., 2013).

O Plano Nacional de Resíduos Sólidos, lançado em 2020, traz um perfil dos combustíveis alternativos e tradicionais utilizados pela indústria brasileira de cimento. Os resíduos fósseis representam $80 \%$ do poder calorífero utilizado para produção de clínquer e o restante constituído de $12 \%$ de combustíveis fósseis alternativos, cinco por cento (5\%) de combustíveis de biomassa (moinha de carvão vegetal), três por cento (3\%) de combustíveis de biomassa (resíduos). Estima-se que em 2016 o Brasil tenha produzido 1.276.199.686 toneladas de resíduos sólidos industriais sólidos e $490.650 \mathrm{~m}^{3}$ para os classificados como líquidos. Já o perfil dos resíduos coprocessados é representado da seguinte maneira: $89 \%$ servem combustíveis alternativos e 11\% como matérias-primas. Os resíduos correspondem a uma substituição térmica média de 14,77\% no país.

Dos substitutos de combustíveis fósseis e matérias-primas coprocessadas destacam-se os pneus inservíveis (53\%), o blend, que é uma mistura de resíduos (36\%), serragem impregnada com óleo, solos contaminados e solventes (9\%), além de óleo usado (2\%). Das matérias-primas alternativas: spent pot linning (SPL) - tipo de resíduo da indústria de petróleo (40\%), solos contaminados (22\%), carepa (13\%), outros (11\%), areia de fundição (10\%) e de terra de Shredder (4\%) (ABCP, 2020).

Já o clínquer é produzido a partir de matérias-primas como calcário e argila, que são esmagados, homogeneizados e alimentados em um forno rotativo existentes nas cimenteiras. As matérias-primas são sintetizadas a uma temperatura de $1.450^{\circ} \mathrm{C}$ para formar novas libras. O clínquer consiste principalmente de óxidos de cálcio, silício, alumínio e ferro. Em uma segunda fase, sulfatos de cálcio e possivelmente materiais cimentícios ou inertes adicionais são incluídos.

Huang et al. (2012) alertaram para emissões excessivas de metais pesados na China devido à utilização descontrolada do coprocessamento de resíduos nos fornos. No Japão, tal problema é reduzido devido a um amadurecido sistema de classificação e gerenciamento de resíduos (LI et al., 2015).

Atualmente, no Brasil tem, aproximadamente, vinte blendeiras e trinta e oito fornos de cimento licenciados para coprocessamento ( $A B C P, 2020)$. A coincineração de resíduos tem crescido de forma significativa e inadequada no país, podendo ocasionar impactos negativos sobre a saúde humana e o meio ambiente (MILANEZ et al., 2009).

Tendo em vista que o coprocessamento em fornos de clinquer é o segundo principal destino dos resíduos industriais, é imprescindível avaliar os impactos ambientais desta cadeia como um todo, verificando se os resíduos industriais que possuem alto potencial poluidor e tóxico influenciam nestas atividades. 


\section{METODOLOGIA}

O método da Avaliação do Ciclo de Vida (ACV) tem como principais referências as normas técnicas brasileiras (NBR) ISO 14040 (ABNT, 2009a) e NBR ISSO 14044 (ABNT, 2009b), que buscam avaliar os impactos ambientais de um produto ou serviço desde o seu surgimento até o descarte final (do berço ao túmulo). Essa técnica compreende quatro etapas: 1a) objetivo e escopo; 2a) inventário do ciclo de vida; $3^{a}$ ) avaliação do impacto do ciclo de vida; e 4a) interpretação.

\section{Objetivo e Escopo}

O objetivo geral do estudo é identificar os principais impactos ambientais da cadeia do processamento de resíduos industriais na produção de clínquer. As fronteiras de sistema do estudo compreendem desde o tratamento do resíduo até a produção do clínquer numa abordagem do berço ao portão. A unidade funcional escolhida foi a produção de uma tonelada de clínquer.

O sistema de produto do coprocessamento é composto pelas seguintes unidades de processo: o transporte, a blendagem e a clinquerização. Nesta seção, será feito o detalhamento das atividades de transporte e produção de clínquer, uma vez que, o detalhamento da blendagem, já foi realizada em capítulo anterior. Em todas essas unidades foram computadas as entradas de matérias-primas e insumos e às saídas de emissões atmosféricas, líquidas e geração de resíduos (Figura 1).

A blendagem consiste no tratamento dos resíduos industriais para serem coprocessados em forno de clínquer sob a forma de uma mistura sólida ou líquida denominada blend. Esta etapa acontece em unidade industrial de homogeneização e mistura de resíduos conhecidas como blendeiras. O perfil da blendagem está baseado em dados de duas unidades situadas no município de Magé na Região Metropolitana do Estado do Rio de Janeiro. A composição dos resíduos sólidos e líquidos utilizados na blendagem é descrita por Aguiar et al. (2021):

[...] solo contaminado $(39,83 \%)$, borra oleosa $(16,35 \%)$, graxas $(8,89 \%)$, resíduos químicos e reagentes diversos $(6,59 \%)$, areia contaminada $(4,08 \%)$, borra de tintas - base de água $(2,96 \%)$, base solvente $(2,29 \%)$-, lodo de ETE $(2 \%)$, resinas $(1,94 \%)$, brita contaminada $(1,87 \%)$, demais resíduos com menos de um por cento (1\%) na composição (11,59\%).

Já os resíduos industriais que formam os blends líquidos apresentaram a seguinte distribuição percentual: lubrificantes $(39,43 \%)$, solventes $(23,54 \%)$, etanol $(9,98 \%)$, sulfonato de alquibenzeno $(5,33 \%)$, álcoois etoxilados $(5,25 \%)$, sulfato de ferro $(4,25 \%)$, diesel $(2,69 \%)$, ácido fosfórico $(2,04 \%)$, formaldeído $(1,61 \%)$, ácido graxo $(1,32 \%)$, óleos $(1,32 \%)$, água oleosa $(1,01 \%)$ e os demais resíduos líquidos menores que $1 \%$ na composição $(5,23 \%)$. Foi computada, também, a entrada de agentes estruturantes e químicos, como maravalha (serragem) e cal virgem, respectivamente, que são misturados aos resíduos na blendagem. (INEA, 2019)

A etapa do transporte foi o resultado da unificação de dois trechos: (a) primeiramente, as distâncias entre os empreendimentos geradores dos resíduos e às unidades de blendagem situadas na cidade de MagéRJ; e (b) em segundo lugar, o transporte dos blends preparados nas blendeiras até às cimenteiras localizadas no município de Cantagalo-RJ para serem coprocessados. A estimativa das distâncias de cada rota de transporte foi realizada através do uso do aplicativo Google Maps. O processo Transport, lorry >32t, EURO5/RER U foi escolhido através do software SimaPro 7.2 para representar o veículo transportador com 
capacidade para transportar 32 toneladas de carga. Acima dessa massa foi computado o número de viagens necessárias à logística de toda a carga até a blendeira de destino. Foi feita a opção das rotas com as menores distâncias, considerando apenas o trajeto de ida, justificado pela incerteza se o veículo transportador necessariamente voltaria ao mesmo local de geração do resíduo ou não. Com base na distância e na carga transportada, foi calculado o tkm com a seguinte fórmula abaixo e inserida no referido software para cálculo do impacto:

$\mathrm{Tkm}=\mathrm{t} . \mathrm{km}$

A clinquerização, ou seja, o coprocessamento propriamente dito ocorre em fornos de via seca. 0 perfil desta etapa foi baseado na produção média anual de 530.330 toneladas de clínquer entre três cimenteiras do Polo de Cantagalo-RJ, município situado na Região Serrana do Estado do Rio de Janeiro. O mix energético é baseado no perfil mássico em toneladas de $91 \%$ de coque, seis por cento (6\%) de blends sólidos e três por cento (3\%) de blends líquidos. É importante destacar que todas as plantas possuem área de lavra específica para retirada de matéria-prima (jazida) próximas as suas instalações. As cimenteiras estão todas situadas num raio próximo de $5 \mathrm{Km}^{2}$.

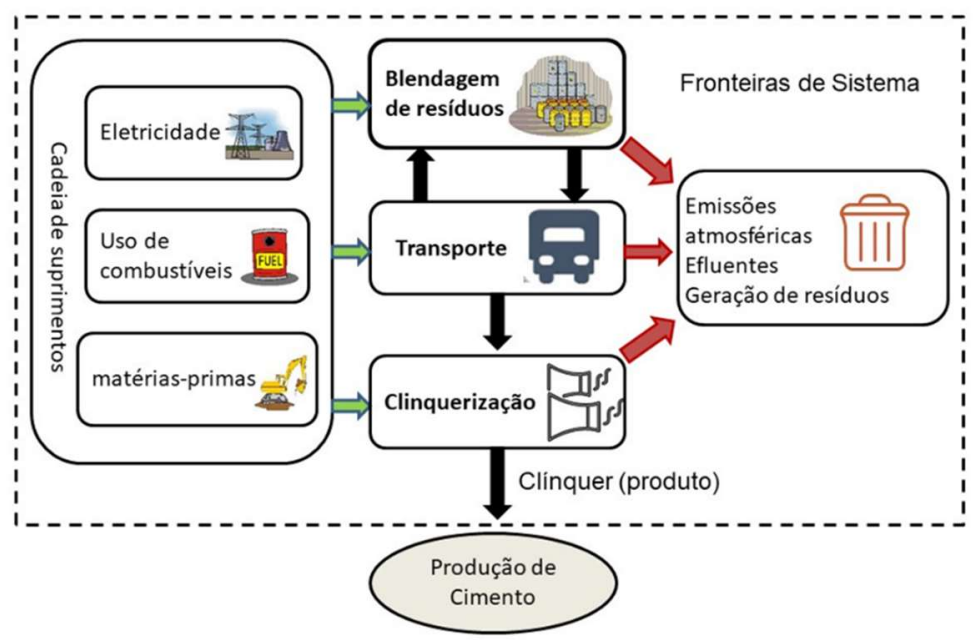

Figura 1: Esquema das fronteiras de sistema.

Todas as informações obtidas em primeiro plano foram extraídas dos processos de licenciamento ambiental. Em segundo plano foi utilizado o banco de dados SimaPro data server 7.2, porém, com um corte mássico das substâncias que contribuíram com menos de cinco por cento (5\%) para os impactos ambientais.

Na Avaliação do Impacto do Ciclo de Vida (AICV), a metodologia escolhida para cálculo dos impactos pelos fatores de caracterização foi o método ReCiPe (HUIJBREGTS et al., 2017), utilizando todas as categorias: Toxicidade Humana (TH), Ecotoxicidade Marinha (ETM), Mudanças Climáticas (MC), Depleção Fóssil (DF), Depleção de Metais (DM), Ocupação da Terra Agrícola (OTA), Radiação lonizante (RI), Depleção da Água (DA), Ecotoxicidade da Água (ETA), Ocupação da Terra Urbana (OTU), Acidificação Terrestre (AT), Formação de Oxidação Fotoquímica (FOF), Ecotoxicidade Terrestre (ET), Formação de Material Particulado (FMP), Eutrofização Marinha (EM), Transformação da Terra Natural (TTN), Eutrofização da Água (EA) e a Depleção do Ozônio (DO).

A seguir, procedeu-se à normalização e continuamente ao agrupamento das categorias de ponto 
médio em apenas três categorias de ponto final: Saúde Humana, Recursos e Ecossistemas sintetizados para toda a cadeia. As ponderações foram realizadas em três grupos: Hierarquist (H), Individualist (I) e Egalitarian (E) que possuem interpretações diferentes (Quadro 1). A seguir, os percentuais foram submetidos à interpretação pelo mixing triangle com a finalidade de identificar a categoria de impacto predominante.

Quadro 1: Grupos de ponderação.

\begin{tabular}{|l|l|l|l|}
\hline Grupos & Perspectiva de tempo & Gestão & Nível de evidência \\
\hline $\begin{array}{l}\text { H } \\
\text { Hierarquista } \\
\text { Hierarchist) }\end{array}$ & $\begin{array}{l}\text { Balanço entre curto e longo } \\
\text { prazo }\end{array}$ & $\begin{array}{l}\text { Políticas apropriadas podem evitar muitos } \\
\text { problemas }\end{array}$ & $\begin{array}{l}\text { Inclusão baseada em } \\
\text { consenso }\end{array}$ \\
\hline $\begin{array}{l}\text { Individualista } \\
\text { (individualist) }\end{array}$ & Curto Prazo & $\begin{array}{l}\text { Tecnologias podem evitar muitos } \\
\text { problemas }\end{array}$ & $\begin{array}{l}\text { Apenas comprovados } \\
\text { com }\end{array}$ \\
\hline $\begin{array}{l}\text { Egalitário } \\
\text { (Egalitarian) }\end{array}$ & Longo Prazo & Problemas podem causar catástrofes & Todos os possíveis efeitos \\
\hline
\end{tabular}

\section{RESULTADOS}

\section{Inventário do Ciclo de Vida}

O resultado do ICV para produção de uma tonelada de clínquer, com os respectivos registros de entrada e saídas de matérias-primas e emissões, respectivamente, são especificados na Tabela 1.

Tabela 1: ICV contendo entradas e saídas para 1t de clínquer.

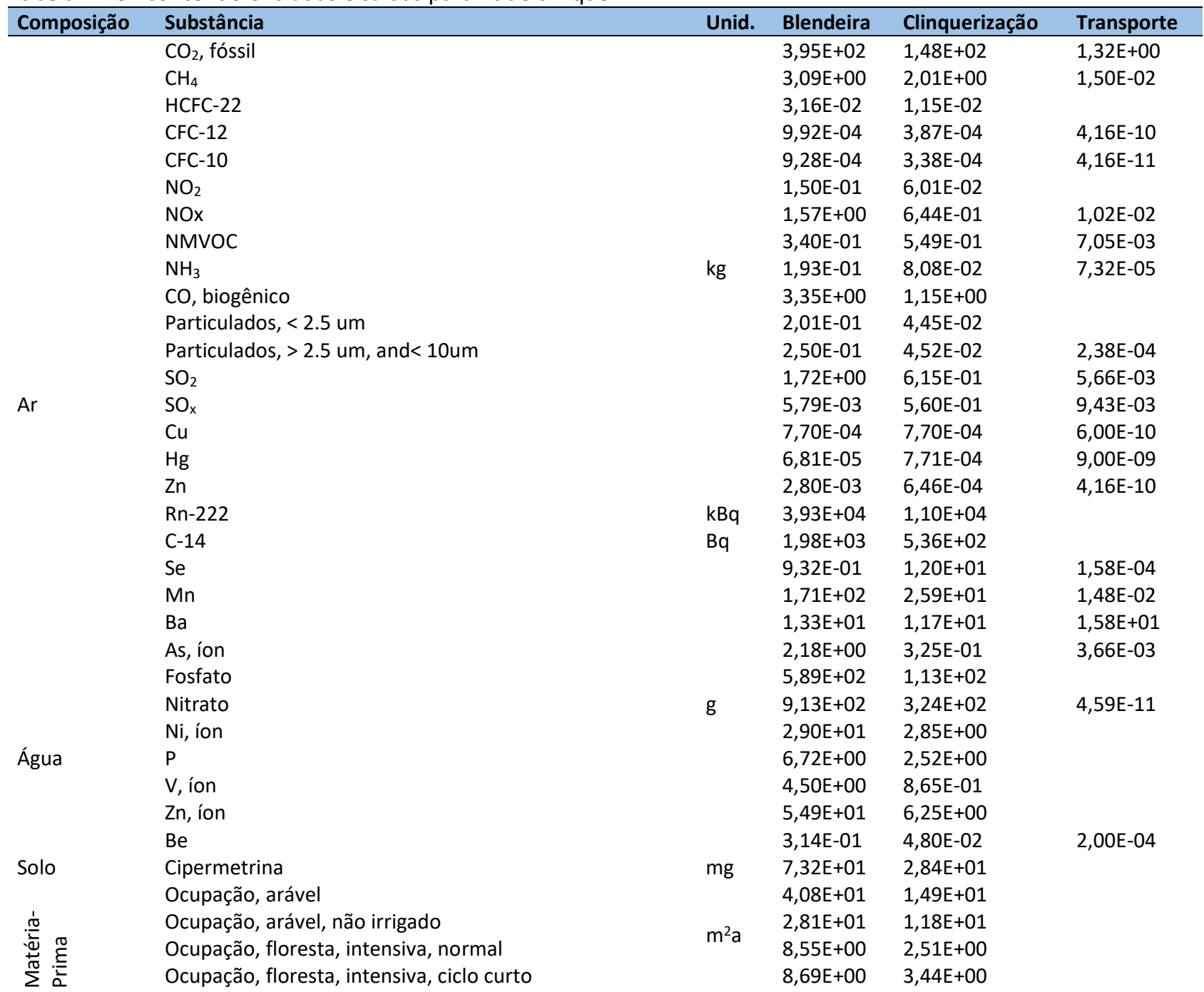




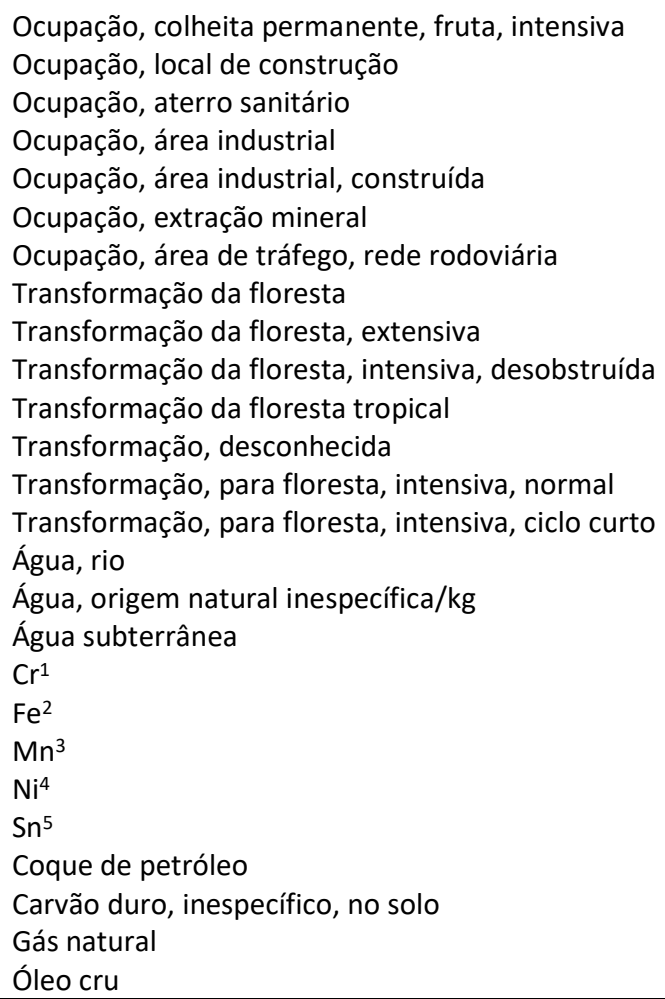

$\begin{array}{ccc} & 1,84 \mathrm{E}+01 & 7,63 \mathrm{E}+00 \\ & 6,20 \mathrm{E}-01 & 2,71 \mathrm{E}-01 \\ & 1,72 \mathrm{E}+00 & 4,75 \mathrm{E}-01 \\ & 3,52 \mathrm{E}-01 & 7,82 \mathrm{E}-02 \\ & 6,15 \mathrm{E}-01 & 1,80 \mathrm{E}-01 \\ & 3,39 \mathrm{E}-01 & 7,76 \mathrm{E}-02 \\ & 2,55 \mathrm{E}-01 & 6,01 \mathrm{E}-02 \\ & 3,61 \mathrm{E}+02 & 1,18 \mathrm{E}+02 \\ & 3,38 \mathrm{E}+01 & 1,31 \mathrm{E}+03 \\ \mathrm{~cm} & 3,19 \mathrm{E}+03 & 1,27 \mathrm{E}+03 \\ & 3,19 \mathrm{E}+03 & 1,27 \mathrm{E}+03 \\ & 5,14 \mathrm{E}+02 & 1,42 \mathrm{E}+02 \\ & 6,36 \mathrm{E}+02 & 1,91 \mathrm{E}+02 \\ & 3,10 \mathrm{E}+03 & 1,23 \mathrm{E}+03 \\ \mathrm{~m}^{3} & 8,00 \mathrm{E}+00 & 3,05 \mathrm{E}+00 \\ & 1,96 \mathrm{E}+02 & 7,13 \mathrm{E}+01 \\ & 1,61 \mathrm{E}+01 & 5,84 \mathrm{E}+00 \\ & 1,01 \mathrm{E}+00 & 4,40 \mathrm{E}-02 \\ & 4,86 \mathrm{E}+01 & 2,27 \mathrm{E}+00 \\ & 7,34 \mathrm{E}-01 & 3,60 \mathrm{E}-02 \\ & 2,60 \mathrm{E}+00 & 1,10 \mathrm{E}-01 \\ \mathrm{~kg} & 4,90 \mathrm{E}-02 & 1,60 \mathrm{E}-03 \\ & 1,22 \mathrm{E}+00 & 1,75 \mathrm{E}+02 \\ & 9,08 \mathrm{E}+01 & 2,00 \mathrm{E}+01 \\ & 4,10 \mathrm{E}+01 & 1,51 \mathrm{E}+01 \\ & 5,91 \mathrm{E}+01 & 2,41 \mathrm{E}+01 \\ & & \end{array}$

$1,90 \mathrm{E}-01$

Notou-se que as principais matérias-primas, segundo o ICV, foi a entrada de um tipo de combustível fóssil, o coque de petróleo, para ser utilizado como combustível para clinquerização. Destaca-se também neste compartimento a entrada de Ferro ( $\mathrm{Fe}$ ) à blendagem, provavelmente, oriundo de borras ricas do elemento, oriundas de atividades como a decapagem, muito comum em indústrias metalúrgicas (CETESB, 2018). Outro recurso natural utilizado é água oriunda de poços artesianos, que é utilizada para lavagem de sucatas (INEA, 2019).

Quanto às emissões atmosféricas, predomina o dióxido de carbono $\left(\mathrm{CO}_{2}\right)$, principalmente na blendagem, que é oriundo dos processos de abastecimento de combustíveis de motores e máquinas (INEA, 2019); já na clinquerização são originadas da descarbonatação (MATOS, 2010).

Para a água, predominam as emissões de nitratos, seguidos de fosfatos oriundos dos efluentes sanitários da blendagem (CETESB, 2021). Já para o solo predominou, tanto na blendagem como na clinquerização, a cipermetrina, que é utilizada como defensivo agrícola na cultura de milho e soja (CETESB, 2010). Cabe ressaltar que resíduos de amido e óleo de soja foram listados como resíduos incorporados pela blendagem (INEA, 2019).

\section{Avaliação de Impacto do Ciclo de Vida}

Os resultados da caracterização dos impactos pelo método ReCiPe podem ser visualizados na Tabela 2.

\footnotetext{
${ }^{1} 25,5 \%$ de cromita, $11,6 \%$ de minério bruto, no solo. $246 \%$ de minério, $25 \%$ de minério bruto, no solo.

${ }^{3} 35,7 \%$ em depósito sedimentar, $14,2 \%$ em minério bruto, no solo.

${ }^{4} 1,98 \%$ em silicatos, $1,04 \%$ em minério bruto, no solo.

${ }^{5} 79 \%$ em cassiterita, $0,1 \%$ em minério bruto, no solo.
} 
Tabela 2: Resultados da caracterização dos impactos.

\begin{tabular}{|c|c|c|c|c|}
\hline Caracterização de impacto & Unidade & Blendeira & Clínquer & Transporte \\
\hline $\mathrm{TH}$ & kg 1,4 DB eq & $8,70 \mathrm{E}+03$ & $5,17 \mathrm{E}+04$ & $1,05 E+03$ \\
\hline ETM & $\operatorname{kg} 1,4 \mathrm{DB}$ eq & $7,63 E+03$ & $1,50 E+04$ & $2,45 \mathrm{E}+02$ \\
\hline MC & $\mathrm{kgCO}_{2} \mathrm{eq}$ & $5,01 E+02$ & $1,94 \mathrm{E}+02$ & $1,44 \mathrm{E}+00$ \\
\hline DF & kgoileq & $1,75 \mathrm{E}+02$ & $1,71 \mathrm{E}+02$ & $4,21 E+00$ \\
\hline DM & kg Fe eq & $2,65 E+02$ & $1,75 E+01$ & $0,00 E+00$ \\
\hline OTA & $\mathrm{m}^{2} \mathrm{a}$ & $1,06 \mathrm{E}+02$ & $4,09 E+01$ & $0,00 E+00$ \\
\hline RI & $\mathrm{kg} \mathrm{U235} \mathrm{eq}$ & $6,49 E+01$ & $1,80 E+01$ & $0,00 E+00$ \\
\hline DA & $\mathrm{m}^{3}$ & $2,62 E+01$ & $9,45 E+00$ & $0,00 E+00$ \\
\hline ETA & $\operatorname{kg} 1,4 \mathrm{DB}$ eq & $6,17 E+00$ & $2,06 \mathrm{E}+00$ & 4,29E-02 \\
\hline OTU & $m^{2} a$ & $4,35 E+00$ & $1,27 \mathrm{E}+00$ & $0,00 E+00$ \\
\hline AT & $\mathrm{kg} \mathrm{SO} 2 \mathrm{eq}$ & $3,51 \mathrm{E}+00$ & $1,91 E+00$ & $2,29 \mathrm{E}-02$ \\
\hline FOF & kg NMVOC eq & $2,52 E+00$ & $1,47 E+00$ & $2,14 \mathrm{E}-02$ \\
\hline ET & kg 1,4 DB eq & $1,69 \mathrm{E}+00$ & $5,48 \mathrm{E}-01$ & $8,83 \mathrm{E}-05$ \\
\hline FMP & kg PM10 eq & $1,24 \mathrm{E}+00$ & $5,07 \mathrm{E}-01$ & $5,61 E-03$ \\
\hline EM & $\mathrm{kg} \mathrm{N} \mathrm{eq}$ & $9,13 \mathrm{E}-01$ & $3,63 \mathrm{E}-01$ & $4,25 E-03$ \\
\hline TTN & $\mathrm{m}^{2}$ & $3,35 \mathrm{E}-01$ & 1,31E-01 & $0,00 E+00$ \\
\hline EA & kg P eq & $2,02 \mathrm{E}-01$ & $4,00 E-02$ & $0,00 E+00$ \\
\hline DO & kg CFC-11 eq & $3,32 \mathrm{E}-03$ & $1,24 \mathrm{E}-03$ & $4,49 E-10$ \\
\hline
\end{tabular}

A caracterização indicou que a etapa da blendagem foi a que apresentou o pior desempenho ambiental, sendo menos impactante que a clinquerização apenas nas categorias ETM, MC, TH e DF. Em relação às outras unidades do sistema de produto, o transporte se mostrou como o menos impactante (Figura 2).

Por outro lado, a normalização indicou a TH como o principal impacto, primeiramente na Clinquerização e logo a seguir na blendagem. A clinquerização foi responsável por $85 \%$ dos impactos. Pinto Júnior et al. (2009) já haviam registrado os efeitos na saúde humana dos trabalhadores da cimenteira pelo manejo de resíduos. Nota-se também que a queima libera, através das emissões atmosféricas, muitos poluentes que podem atingir a população da região (Figura 3).

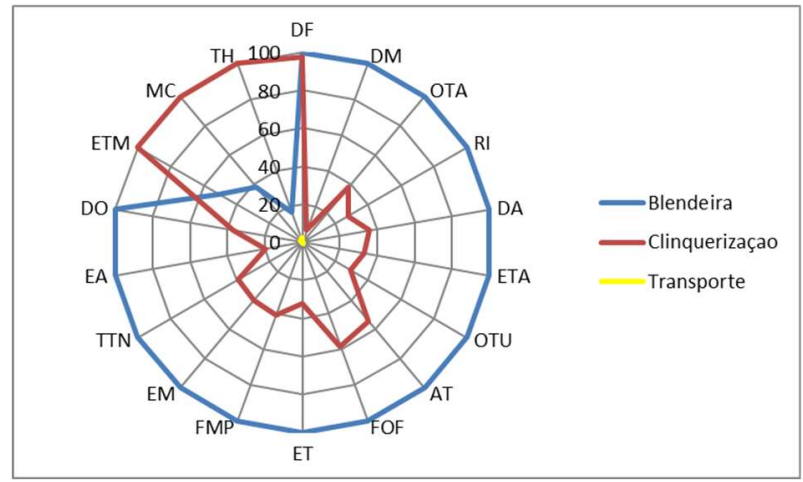

Figura 2: Desempenho Ambiental das unidades da cadeia do coprocessamento.

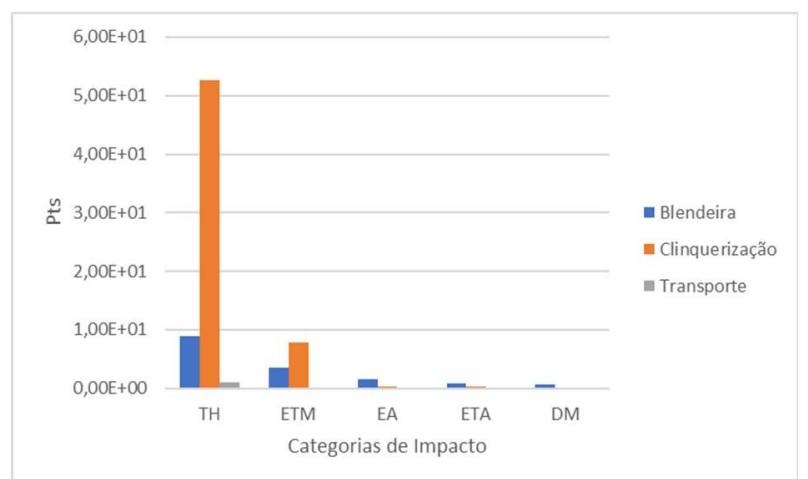

Figura 3: Principais impactos de ponto médio da cadeia de coprocessamento.

Quanto à Ecotoxidade Marinha, podemos destacar que as blendeiras estão localizadas na Bacia da Baía de Guanabara, próximas à APA de Guapimirim, onde predomina o ecossistema manguezal, berçário de muitas espécies. Os efluentes industriais da blendeira podem atingir a unidade de conservação através do Rio Iriri, ameaçando assim diversas espécies marinhas e a avifauna típica dos manguezais. Outro impacto significante é a EA, provocado por substância à base de $\mathrm{N}$ e $\mathrm{P}$, que poderão afetar a qualidade ambiental das águas pelo aporte de nutrientes, favorecendo a proliferação de algas e a queda das taxas de $\mathrm{O}_{2}$ dissolvido, reduzindo a biodiversidade nesta bacia. 
A seguir, nota-se, também em segundo lugar, o impacto da Ecotoxicidade Marinha na clinquerização e na blendagem. É importante salientar que o polo cimenteiro está localizado na Região Serrana, afastado do ambiente marinho; porém, é importante monitorar a qualidade dos rios da bacia à jusante pela possibilidade do impacto tanto nos recursos hídricos como na foz ou região de estuário ou manguezal nas baixadas.

\section{DISCUSSÃO}

\section{Interpretação}

Submetendo os resultados aos três grupos de ponderação diferentes, notou-se que, quanto ao impacto que se manifesta a curto prazo, o predominante é a Qualidade dos Ecossistemas. Já os impactos gerados à Saúde Humana são predominantes a médio e longo prazos. Tal fato pode ser explicado pelo mecanismo inerentes às substâncias, que provocam impactos que, primeiramente, afetam a qualidade do ambiente e, posteriormente, através dos mecanismos de absorção, os efeitos passam a se manifestar na saúde (ROCHA, 2017).

Tabela 3: Ponderação dos resultados.

\begin{tabular}{llll}
\hline Grupo & Recursos & Saúde Humana & Qualidade dos Ecossistemas \\
\hline H & $38 \%$ & $17 \%$ & $45 \%$ \\
I & $39 \%$ & $54 \%$ & $7 \%$ \\
E & $8 \%$ & $89 \%$ & $3 \%$ \\
\hline
\end{tabular}

Portanto, submetendo conjuntamente as ponderações à análise no mixing triangle, o padrão confirma que o impacto da cadeia de coprocessamento é predominante na Saúde Humana (Figura 4).

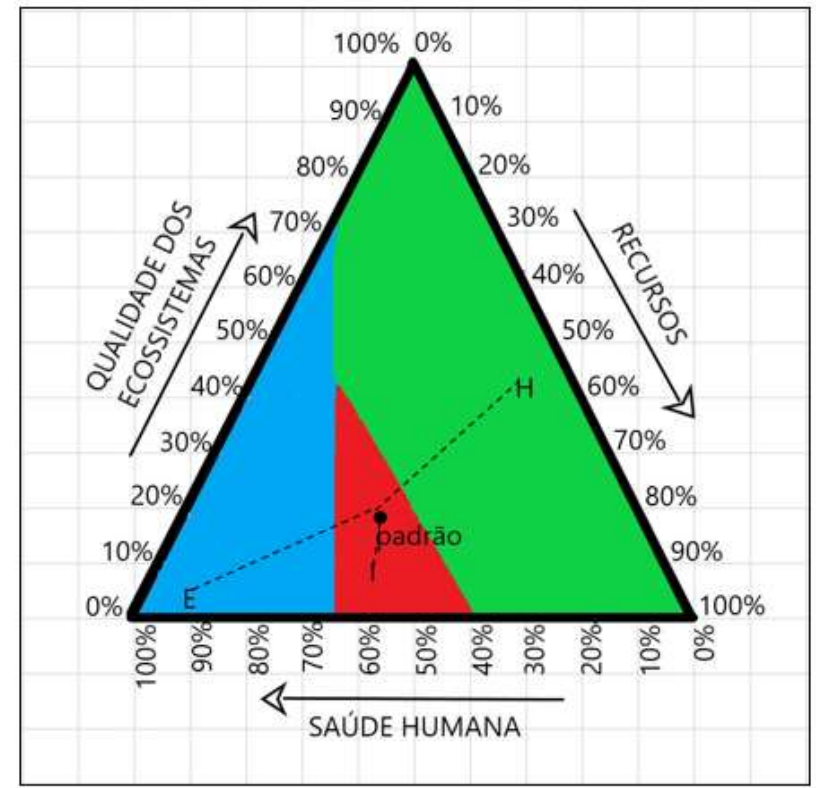

Figura 4: Relações entre as ponderações pelo mixing triangle.

\section{CONCLUSÕES}

Considerando a ACV realizada na cadeia do coprocessamento de resíduos, concluiu-se que a clinquerização é a etapa mais impactante na referida cadeia, sendo a TH o seu principal impacto, em ponto 
médio. Globalmente, com base nas ponderações feitas em diferentes grupos, concluiu-se também que o principal impacto foi à Saúde Humana, em ponto final.

Tal conclusão permite observar, primeiramente, que a causa principal está nas substâncias tóxicas existentes nos resíduos industriais, culminando em riscos ocupacionais na blendagem e potencializando-se na queima do resíduo no forno de clínquer.

Nota-se que em ambas as atividades, a proximidade dos trabalhadores com os resíduos pelo manejo os expõe ao contato com inúmeras substâncias tóxicas e perigosas, tendo como portas de entrada a via respiratória através das emissões e odores. Os impactos também podem se estender às populações vizinhas e aos empreendimentos em casos de ocupação urbana e residencial. As análises demostram a possibilidade de evolução dos efeitos da toxicidade ocasionados pelos mecanismos de interação entre as substâncias com os organismos humanos, manifestando desde sintomas, passando pelo desenvolvimento de doenças, até a possibilidade de câncer.

Quanto ao impacto aos ecossistemas, destacou-se negativamente a ETM. A ETM apresenta uma maior ameaça no contexto geográfico à região onde se encontram as blendeiras, por estarem situadas no entorno de áreas protegidas sensíveis de manguezais da Baía de Guanabara. O ponto de contato se dá, principalmente, pelo lançamento de efluentes das blendeiras no Rio Iriri e Santo Aleixo, que recebem os efluentes de uma das blendeiras estudadas. Já tal impacto não apresenta o mesmo potencial para a Região Serrana do Estado, onde estão localizados os fornos de coprocessamento.

Outros potenciais impactos que devem ser monitorados estão diretamente relacionados à qualidade dos recursos hídricos, que são a ETA e EA. Sendo assim, os rios e as bacias hidrográficas das regiões onde estão situadas as blendeiras e cimenteiras podem sofrer com o principais efeitos da toxicidade e da eutrofização da água, culminando com a perda da qualidade para o abastecimento humano e da biota aquática, acarretando na redução da biodiversidade da comunidade biológica, refletindo negativamente em atividades econômicas de subsistência, como a pesca.

Então, recomenda-se: que os diversos setores da indústria e do comércio possam implantar programas de prevenção à poluição, fazendo com que um percentual maior de resíduos possa ser aproveitado em linhas diversas de reciclagem ao invés de serem diretamente submetidos às blendeiras, ou seja, maior rigor na gestão eficiente de resíduos; Recomenda-se, igualmente, a reavaliação completa das atividades de blendagem pelos órgãos de controle, exigindo dos empreendedores a elaboração de estudos de automação de seus processos, visando reduzir ao máximo a manipulação direta dos resíduos pelo trabalhador e a decorrente exposição a odores tóxicos e outros perigos; indica-se a realização de estudos epidemiológicos dos trabalhadores das blendeiras e cimenteiras e da população circundante, com a realização futura de ACV social e econômica para complementação desses estudos. Recomenda-se aos órgãos de controle um monitoramento mais severo de metais no solo e na água e de gases e particulados na atmosfera nas áreas de influência das blendeiras e cimenteiras. Todas estas recomendações direcionam-se à profilaxia dos impactos gerados ao meio ambiente e à saúde humana. 


\section{REFERÊNCIAS}

AGUIAR, D. M.; MATTOS, U. A. O.; ESTEVES, V. P. P.. Avaliação do ciclo de vida na fabricação de clínquer em diferentes cenários energéticos. Revista Ibero-Americana de Ciências Ambientais, v.12, n.6, 2021.

$A B C P$. Associação Brasileira de Cimento Portland. Unidades de coprocessamento no Brasil. São Paulo: ABCP, 2020.

ABNT. Associação Brasileira de Normas Técnicas. ABNT NBR ISO 14040: gestão ambiental - Avaliação do ciclo de vida princípios e estrutura. Rio de Janeiro: ABNT, 2009a.

ABNT. Associação Brasileira de Normas Técnicas. ABNT NBR ISO 14044: gestão ambiental - avaliação do ciclo de vida requisitos e orientações. Rio de Janeiro: ABNT, 2009b.

BOESCH, M. E.; HELLWEG, S.. Identifying improvement potentials in cement production with life cycle assessment. Environmental Science \& Technology, v.44, n.23, p.91439149, 2010. DOI: https://doi.org/10.1021/es100771k

CETESB. Companhia Ambiental do Estado de São Paulo. Águas subterrâneas. São Paulo: CETESB, 2021.

CETESB. Companhia Ambiental do Estado de São Paulo. Fundamentos do controle de poluição das águas. São Paulo: CETESB, 2018.

CETESB. Companhia Ambiental do Estado de São Paulo. Proposta para derivação de critérios para contaminantes ambientais da agricultura: relatório final. São Paulo: CETESB, 2010.

HUANG, Q.; YANG, Y.; QI, W.. Potential for serious environmental threats from uncontrolled coprocessing of wastes in cement kilns. Environmental Science \& Technology, v.46, n.24, p.13031-13032, 2012. DOI: https://doi.org/10.1021/es3042274
HUIJBREGTS, M. A. J.; STEINMANN, Z. J. N.; ELSHOUT, P. M. F.; STAM, G.; VERONES, F.; VIEIRA M.; ZIJP, M.; HOLLANDER, A.; VAN ZELM, R.. ReCiPe2016: a harmonized life cycle impact assessment method at midpoint and endpoint level. The International Journal of Life Cycle Assessment, v.22, p.138-147, 2017.

INEA. Instituto Estadual do Ambiente. Portal do Licenciamento. Rio de Janeiro: INEA, 2019.

LAMAS, W. Q.; PALAU, J. C. F.; CAMARGO, J. R.. Waste materials co-processing in cement industry: ecological efficiency of waste reuse. Renewable and Sustainable Energy Reviews, v.19, p.200-207, 2013. DOI: https://doi.org/10.1016/j.rser.2012.11.015

LI, C.; CUI, S.; NIE, Z.; GONG, X.; WANG, Z.; ITSUBO, N.. The LCA Portland cement production in China. The International Journal of Life Cycle Assessment, v.20, p.117-127, 2015. DOI: https://doi.org/10.1007/s11367-014-0804-4

MATOS, A. T... Poluição ambiental: impactos no meio físico. Viçosa: UFV, 2010.

MILANEZ, B.; FERNANDES, L. O.; PORTO, M. F. S.. A

Coincineração de resíduos em fornos de cimento: riscos para a saúde e o meio ambiente. Ciência \& Saúde Coletiva, v.14, n.6, p.2143-2152, 2009. DOI:

https://doi.org/10.1590/S1413-81232009000600021

PINTO JÚNIOR, A. G. P.; BRAGA, A. M. C. B.. Trabalho e saúde: a atividade da queima de resíduos tóxicos em fornos de cimenteiras de Cantagalo, Rio de Janeiro. Ciência \& Saúde Coletiva, v.14, n.6, p.2005-2014, 2009. DOI: http://dx.doi.org/10.1590/S1413-81232009000600008

ROCHA, T. B.. Curso de avaliação do ciclo de vida: Interpretação. Curitiba: ACV Brasil, 2017.

A CBPC - Companhia Brasileira de Produção Científica (CNPJ: 11.221.422/0001-03) detém os direitos materiais desta publicação. Os direitos referem-se à publicação do trabalho em qualquer parte do mundo incluindo os direitos às renovações, expansões e disseminacões da contribuicão, bem como outros direitos subsidiários. Todos os trabalhos publicados eletronicamente poderão posteriormente ser publicados em coletâneas impressas sob coordenação da Sustenere Publishing, da Companhia Brasileira de Produção Científica e seus parceiros autorizados. Os (as) autores (as) preservam os direitos autorais, mas não têm permissão para a publicação da contribuição em outro meio, impresso ou digital, em português ou em tradução. 